\title{
Vascular physiotherapy: a strategy for treatment of chronic venous disease
}

\author{
Fisioterapia vascular: estratégia no tratamento da doença venosa crônica \\ Rodrigo Pegado de Abreu Freitas', Georges Willeneuve de Souza Oliveira², \\ Maria Thereza Albuquerque Barbosa Cabral Micussi ${ }^{1}$
}

We read with great interest the recent manuscript by Leal et al. ${ }^{1}$ entitled "Vascular physiotherapy in treatment of chronic venous disease". The authors investigate the results of a supervised rehabilitation protocol including warm-up, training and relaxation. The training protocol consisted of vascular kinesiotherapy using manual lymph drainage and resistance and aerobic exercises. The importance of this type of study is unquestionable since chronic venous disease (CVD) affects a considerable proportion of the worldwide population and can involve chronic wounds and disability. ${ }^{2}$ This is an initial treatment for CVD and its aim is to reduce symptoms and help prevent the development of secondary complications and disease progression. $^{3}$

However, another preliminary therapeutic option for all CEAP clinical classes of CVD is continuous compression therapy. ${ }^{3}$ In this case, the objective is to administer graded external compression to the leg, opposing the hydrostatic forces of venous hypertension. ${ }^{3}$ A number of compression garments are available including elastic compression stockings, multilayer elastic wraps, dressings, elastic and nonelastic bandages and nonelastic garments. ${ }^{3}$ The American College of Phlebology strongly recommends compression therapy as an effective method for the management of symptoms related to CVD. ${ }^{4}$ These recommendations apply to most patients in most circumstances without reservations. ${ }^{3,4}$ It is clear that the results of the treatment protocol applied by Leal et al. ${ }^{1}$ were good, but they could have been enhanced by addition of elastic compression stockings or nonelastic bandages worn during the exercise protocol and afterwards. ${ }^{5}$ Treatment with 30 to $40 \mathrm{~mm} \mathrm{Hg}$ compression stockings results in significant improvement in pain, swelling, skin pigmentation, activity, and well-being if compliance of $70 \%$ to $80 \%$ is achieved. ${ }^{5}$ Compression stockings have been shown to reduce the residual volume fraction, which is an indicator of improved calf muscle pump function, and they also reduce reflux in vein segments. ${ }^{5}$

Another important question is standardization of exercises prescribed for CVD. Structured exercise improves calf muscle pump function in chronic venous insufficiency and the efficacy of physical conditioning has been convincingly demonstrated in patients with chronic venous disease, but none of the practice guidelines for treatment of chronic venous disease describe the aerobic or strength training used in detail..$^{5-7}$ Perhaps this is the reason Leal et al. ${ }^{1}$ did not provide details of the aerobic and resistance exercises prescribed. If the objective of physical treatment is to improve calf muscle pump function, we suggest following the American College of Sports Medicine's guidelines for exercise prescription. ${ }^{7}$ These recommendations may also be applied to adults with certain chronic diseases or disabilities, when appropriately evaluated and advised by a health professional.

In conclusion, the vascular physiotherapy protocol for treatment of chronic venous disease conducted by Leal et al. ${ }^{1}$ achieved important results and could be enhanced with compression garments. The protocol with resistance and aerobic exercises could have been explained in greater detail in order that it could be reproduced by other health professionals.

\section{REFERENCES}

1. Leal FJ, Couto RC, Silva TP, Tenório V. Vascular physiotherapy in treatment of chronic venous disease. J Vasc Bras. 2015;14(3):22430. http://dx.doi.org/10.1590/1677-5449.0029.

2. Lal BK. Venous ulcers of the lower extremity: definition, epidemiology, and economic and social burdens. Semin Vasc Surg. 2015;28(1):3-5. http://dx.doi.org/10.1053/j.semvascsurg.2015.05.002. PMid:26358303.

\footnotetext{
Universidade Federal do Rio Grande do Norte - UFRN, Natal, RN, Brazil. ${ }^{2}$ Universidade Potiguar - UnP, Mossoró, RN, Brazil.

Financial support: None.

Conflicts of interest: No conflicts of interest declared concerning the publication of this article.

Submitted: October 29, 2015. Accepted: December 27, 2015.
} 
3. Eberhardt RT, Raffetto JD. Chronic venous insufficiency. Circulation. 2005;111(18):2398-409. http://dx.doi.org/10.1161/01. CIR.0000164199.72440.08. PMid:15883226.

4. Gloviczki P, Comerota AJ, Dalsing MC, et al. The care of patients with varicose veins and associated chronic venous diseases: clinical practice guidelines of the Society for Vascular Surgery and the American Venous Forum. J Vasc Surg. 2011;53(5, Suppl):2S-48S. http://dx.doi.org/10.1016/j.jvs.2011.01.079. PMid:21536172.

5. Khilnani NM, Grassi C), Kundu S, et al. Multi-society Consensus Quality Improvement Guidelines for the Treatment of Lowerextremity Superficial Venous Insufficiency with Endovenous Thermal Ablation from the Society of Interventional Radiology, Cardiovascular Interventional Radiological Society. J Vasc Interv Radiol. 2010;21(1):14-31. http://dx.doi.org/10.1016/j.jvir.2009.01.034. PMid:20123189.

6. Padberg FT Jr, Johnston MV, Sisto SA. Structured exercise improves calf muscle pump function in chronic venous insufficiency: a randomized trial. J Vasc Surg. 2004;39(1):79-87. http://dx.doi. org/10.1016/j.jvs.2003.09.036. PMid:14718821.

7. Garber CE, Blissmer B, Deschenes MR, et al. Quantity and quality of exercise for developing and maintaining cardiorespiratory, musculoskeletal, and neuromotor fitness in apparently healthy adults: guidance for prescribing exercise. Med Sci Sports Exerc. 2011;43(7):1334-59. http://dx.doi.org/10.1249/MSS.0b013e318213fefb. PMid:21694556.

Correspondence Rodrigo Pegado de Abreu Freitas Universidade Federal do Rio Grande do Norte - UFRN, Faculdade de

Ciências da Saúde do Trair Rua Trairí, s/n - Centro CEP 59200-000 - Natal (RN), Brazi Tel.: +55 (84) 99915-0043 E-mail: rodrigopegado@gmail.com

Author information RPAF - PhD; Physiotherapist; Professor of Cardiovascular Rehabilitation, Universidade Federal do Rio Grande do Norte (UFRN). GWSO - MSC; Physiotherapist; Professor of Cardiovascular Rehabilitation, Universidade Potiguar. MTABCM - PhD; Physiotherapist; Professor of Women's Health, Universidade Federal do Rio Grande do Norte (UFRN) 